\title{
The impact of horizontal gene transfer on the adaptive ability of the human oral microbiome
}

\author{
Adam P. Roberts ${ }^{1 *}$ and Jens Kreth ${ }^{2}$ \\ 1 Department of Microbial Diseases, UCL Eastman Dental Institute, University College London, London, UK \\ ${ }^{2}$ Department of Microbiology and Immunology, College of Medicine, University of Oklahoma Health Sciences Center, Oklahoma City, OK, USA
}

\section{Edited by:}

Alex Mira, Center for Advanced

Research in Public Health, Spain

\section{Reviewed by:}

Nick Stephen Jakubovics,

Newcastle University, UK

Valerio lebba, 'Sapienza' University

of Rome, Italy

*Correspondence:

Adam P. Roberts, Department of Microbial Diseases, UCL Eastman

Dental Institute, University College

London, 256 Gray's Inn Road,

London, WC1X 8LD, UK

e-mail:adam.roberts@ucl.ac.uk
The oral microbiome is composed of a multitude of different species of bacteria, each capable of occupying one or more of the many different niches found within the human oral cavity. This community exhibits many types of complex interactions which enable it to colonize and rapidly respond to changes in the environment in which they live. One of these interactions is the transfer, or acquisition, of DNA within this environment, either from co-resident bacterial species or from exogenous sources. Horizontal gene transfer in the oral cavity gives some of the resident bacteria the opportunity to sample a truly enormous metagenome affording them considerable adaptive potential which may be key to survival in such a varying environment. In this review the underlying mechanisms of HGT are discussed in relation to the oral microbiome with numerous examples described where the direct acquisition of exogenous DNA has contributed to the fitness of the bacterial host within the human oral cavity.

Keywords: horizontal gene transfer, mobile genetic elements, conjugation, transformation, hydrogen peroxide, extracellular DNA, oral cavity, biofilm

\section{INTRODUCTION}

The human oral microbiome is an incredible example of a species rich collection of micro-organisms living together primarily as a multispecies biofilm. The constant challenges the biofilm inhabitants have to cope with include interactions of co-operation and antagonism whilst the individual cells have to adjust to an ever changing onslaught of environmental perturbations. Availability of carbohydrate sources, temperature changes and the interaction with transient, non-oral species of bacteria are just a few examples of the challenges the individual members of the multispecies oral biofilm have to adjust to.

There are many recent reviews concerning the actual numbers, and species composition, of bacteria within the human oral cavity and the reader is directed to these (e.g., Curtis et al., 2011; Wade, 2013), and accompanying articles in this special issue for the background knowledge on the composition of this community.

The dynamic environment of the oral cavity pressures cells of the oral biofilm to not only adjust at the metabolic level but also evolve their genomic content and potential. The species richness and diversity of the oral cavity creates complex bacterial interactions including the exchange of genetic material via horizontal gene transfer (HGT). A recent study on the genome evolution of the genus Streptococcus, which is the most abundant genus in the oral cavity (Rosan and Lamont, 2000; Diaz et al., 2006), demonstrated HGT as important mechanism for the acquisition of new genetic traits and significantly contributed to the genomic expansion and streamlining of Streptococcus (Richards et al., 2014). Indeed Smillie et al have recently shown that the driver for HGT between bacteria is primarily due to the ecology with most gene transfers (determined where genes are $>99 \%$ identical at the nucleotide level in different bacteria) occurring in bacteria from ecologically similar environments (Smillie et al., 2011) and is less dependent on geography or phylogeny of the microbial community. This makes strategic sense for the organisms which inhabit these different ecological niches as the available, accessory metagenome will be enriched for genes which allow adaption to local stresses and maximization of opportunities within a particular environment. Each environment will have an individual, and often unique, set of parameters which must be tolerated and exploited by the microbial inhabitants in order to successfully colonize that environment over time.

\section{THE VARIABLE ORAL ENVIRONMENT}

The oral cavity is by no means a static environment; rather it is an environment where diverse ecological pressures exist. As a portal to the distal part of the digestive tract the oral cavity is open to the environment and also has a variety of foods (substrates) pass through it. There is therefore a great deal of variability encountered in terms of physical, chemical and physicochemical characteristics.

Bacteria will have to cope with multiple defense mechanisms within the oral cavity including, but not limited to the production of host antimicrobial compounds such as lactoperoxidase and lysozyme, bacterially derived antimicrobials and bacteriocins, production of immunoglobulins $\mathrm{A}, \mathrm{G}$, and $\mathrm{M}$, mucus layers on mucosal surfaces and the constant shedding of epithelial cells. There are also relatively strong mechanical forces which result during chewing, talking and the movement of the tongue. Forces up to 150 Newtons $(\mathrm{N})$ are generated whilst chewing foods such as meat whilst the maximal biting forces have been estimated to be between 500 and $700 \mathrm{~N}$ (Wilson, 2005). In addition to the 
mechanical forces there are also hydrodynamic shear forces that occur due to the flow of saliva and, to a lesser extent gingival crevicular fluid.

Chemically the mouth is a very diverse environment which can be subject to extremely rapid change when food and liquids are consumed. Whilst the main source of nutrients for oral bacteria is the saliva there is a diverse range of carbohydrates and other sources of energy which can be temporarily elevated following feeding and the ability to utilize these substrates rapidly provides an advantage for the microbes. Additionally with so many different species inhabiting the oral cavity, inevitable syntrophic relationships have evolved such as species of Veillonella utilizing the lactate produced by cariogenic streptococci (Chalmers et al., 2008).

Differences in mechanical force, nutritional variation and availability, temperature, $\mathrm{pH}$ levels, oxidative stress and redox potential, presence of both host and bacterially derived antibacterial enzymes all provide challenges to the microbial inhabitants which inevitably select for evolved advantageous traits. When such traits are encoded by mobile DNA this environment will also therefore select for the transfer of such genes to other inhabitants.

\section{HORIZONTAL GENE TRANSFER IN THE ORAL CAVITY}

Conjugation, transduction and transformation are the three main mechanisms of HGT. Conjugation is the direct transfer between live donor and recipient cells in a DNase insensitive manner and is the mechanisms of transfer used by conjugative plasmids and conjugative transposons. Transduction is the transfer of host genomic DNA by bacteriophage which package the host DNA into the bacteriophage head structures and transformation is the uptake of exogenous, extracellular DNA often released from dead bacteria cells in the environment. The mechanics of these three mechanisms have been reviewed in detail previously for specific pathogens (e.g., Lindsay, 2014). Recently however another process involved in HGT has been reported which deserves mention here as it could be directly relevant to the biofilm way of life.

Membrane vesicles are released from the cell surface by many Gram-negative, and some Gram-positive, bacteria and can contain proteins, polysaccharides and importantly for microbial adaptation, DNA (Yaron et al., 2000). This DNA can be utilized by other competent bacteria as a substrate for transformation. Virulence genes, plasmid located antibiotic resistance genes and $g f p$ (encoding green fluorescent protein) have been shown to be exported from Escherichia coli in vesicles and furthermore have been shown to successfully transform Salmonella (Yaron et al., 2000; Mashburn-Warren and Whiteley, 2006). It has been revealed that a small proportion of the membrane vesicles from the psychrotropic bacterium Shewanella have a double membrane and therefore contain cytoplasmic contents, providing a much needed explanation of how DNA can be incorporated into the vesicles without being either transported to the periplasm of the cell or to the external environment and subsequently integrated into a vesicle composed only of the outer membrane (PérezCruz et al., 2013). These DNA containing membrane vesicles have also recently been shown for Acinetobacter baylyi (Fulsundar et al., 2014). More recently, the oral biofilm relevant Streptococcus mutans has been shown to release extracellular DNA (eDNA) via membrane vesicles into the developing biofilm and provides therefore an important source for genetic material via this novel mechanism (Liao et al., 2014).

HGT has been demonstrated to occur between a wide range of bacteria which inhabit the human oral cavity. Using in vitro models both conjugation and transformation have been shown to occur between different species of bacteria (Roberts et al., 1999, 2001; Ready et al., 2006; Hannan et al., 2010) and acquisition of doxycycline resistance encoding transposons has also been demonstrated within a patient receiving doxycycline therapy for the treatment of periodontitis (Warburton et al., 2007). Importantly, gene transfer from transient bacteria unable to colonize oral biofilms themselves has been previously demonstrated to occur from a Bacillus subtilis donor of the conjugative transposon Tn5397 to an oral Streptococcus sp. in a mixed species oral biofilm growing in a constant depth film fermentor (Roberts et al., 1999). Additionally bacterial DNA from transient species has been detected in metagenomic libraries made from DNA isolated from the pooled saliva of 20 healthy individuals (Seville et al., 2009); in this case the likely source of the cloned DNA was from a transient Phytoplasma sp., which usually resides within plant tissues. This work demonstrates that the plasticity of the oral metagenome may be influenced by the members of transient bacteria which interact with the oral community and will depend themselves on the diet and habits of the individual human host.

Whilst there have been no reported observations of transduction in the oral cavity, or relevant in vitro models, there is now good evidence that bacteriophages are abundant in the oral cavity. Studies on saliva have isolated bacteriophages able to lysogenize specific bacterial pathogens such as Enterococcus faecalis (Bachrach et al., 2003; Stevens et al., 2009) and Aggregatibacter actinomycetemcomitans (Sandmeier et al., 1995; Willi et al., 1997). More recently direct observation and metagenomic analysis of viral plaque and saliva fractions have revealed that bacteriophages are extremely common (Al-Jarbou, 2012; Pride et al., 2012). It has been determined that viral particles are present at approximately $10^{8}$ particles per milliliter of saliva and that the vast majority of these particles are bacteriophages that may be a reservoir of genes involved in pathogenicity (Pride et al., 2012).

Recent reviews have summarized examples of HGT within and between species which inhabit the human oral cavity (Roberts and Mullany, 2006, 2010; Olsen et al., 2013) however some individual examples pertaining to life in the oral cavity will be discussed below.

\section{ADHERENCE AND BIOFILM FORMATION}

Many, if not most bacteria which inhabit the oral cavity grow as a biofilm on the non-shedding surfaces of the teeth. Therefore the ability to adhere to the oral surfaces and to grow within a biofilm will give these bacteria a significant advantage in this environment due to the advantages of the biofilm mode of growth, many of which are discussed above. One recent example demonstrating the extent to which HGT can allow an organism to survive, and cause disease in the oral cavity is the recently published genome and transcriptome of Streptococcus parasanguinis FW213 (Geng et al., 2012). The genome of this bacterium contains at least five acquired genomic islands (GIs). The first two GIs, Fwisland_1 and 
Fwisland_2 contain genes which are likely to be involved in the production of the lantibiotic salivaricin B and a lactococcin 972 type bacteriocin respectively. The production of bacteriocins and other bacterial inhibitors, particularly by the oral streptococci, which usually are active against similar bacteria to the producing strain, gives them a clear advantage during growth in a relatively nutrient limited environment such as the oral cavity (see below). The third GI, Fwisland_3 encodes long fimbriae that are involved in enhanced biofilm formation. Fwisland_4 encodes genes whose predicted products are involved with the biogenesis and export of extracellular polysaccharides whose roles in biofilm formation, adherence and resistance to host immune systems, such as phagocytosis are well known. Finally Fwisland_5 encodes genes which are believed to be involved in the modulation of biofilm formation. All of the predicted function of the genes products from the 5 GIs appear to be involved in adaptation to the oral cavity (Geng et al., 2012). A similar contribution of HGT to the genomes of other oral species have also been demonstrated, e.g., Porphyromonas gingivalis (Tribble et al., 2007, 2012; Kerr et al., 2014) and the mitis group streptococci (Zähner et al., 2011). The ability of bacteria to grow as a biofilm within the oral cavity can also protect them from exogenous antibacterial compounds such as disinfectants and antibiotics. Another way HGT can contribute to the survival under antibiotic pressure is to allow the bacteria to acquire specific genes encoding antibiotic resistance proteins which will be discussed in the next section.

\section{ACQUIRED ANTIBIOTIC RESISTANCE AND MOBILE GENETIC ELEMENTS}

One of the most prominent phenotypic advantages a bacterial cell can exhibit is resistance to antimicrobial compounds which are present in great abundance in the oral environment. Acquired antibiotic resistance genes have been found in many species of bacteria which inhabit the oral cavity (Ciric et al., 2012) and additionally recent studies have focussed on metagenomes from the oral cavity (saliva) and have shown a myriad of different resistance genes being present (Seville et al., 2009). Often these resistance genes have been found to be localized on putative and sometimes proven mobile genetic elements (MGEs) (e.g. Ciric et al., 2011, 2014). The conjugative transposon Tn916 is a prime example of a MGE which is found to be responsible for the transfer of a multitude of different resistances in the oral microflora.

Tn916 normally confers tetracycline and minocycline resistance by encoding for the Tet(M) protein, a ribosomal protection protein which reversibly binds to the $23 \mathrm{~S}$ rRNA subunit of the ribosome and prevents tetracycline binding therefore preventing protein synthesis, or removing a bound tetracycline molecule before binding itself (Connell et al., 2003). Tn916 is the paradigm of a large family of MGEs, many of which encode additional resistance genes e.g. elements such as Tn2009 contain erm (B) conferring macrolide, lincosamide and streptogramin resistance, Tn6009 encodes resistance to both inorganic and organic mercury by the action of MerA and MerB respectively and Tn1545 and Tn6003 both encode resistance to kanamycin via the product of $a p h A-3$ (reviewed in Roberts and Mullany, 2011). Interestingly the first antiseptic resistance gene has recently been found associated with a Tn916 like element designated Tn6078. This antiseptic resistance gene; qrg, is itself flanked by two copies of a commonly found insertion sequence IS1216. This composite transposon has inserted into a gene encoding a protein Orf15 which is believed to be essential in the conjugation of the host Tn916-like element. Experimentation failed to demonstrate transfer by conjugation of this element, presumably due to the insertion in orf15, however it was demonstrated that it could successfully transform a competent oral streptococci (Ciric et al., 2011) to CTAB resistance. This study is one of a number to highlight the redundancy in the mechanisms of HGT of resistance genes in this environment and it shows that both conjugation and transformation are important in terms of antimicrobial resistance transfer (Hannan et al., 2010). The regulation of competence and uptake of naked DNA in the oral environment is pervasive and is perhaps the driving force for adaptation in some species of oral bacteria such as the streptococci. Most of the previously mentioned MGEs with their different resistances have recently been found in a survey of oral streptococci from 20 healthy adult UK volunteers who provided saliva (Ciric et al., 2012) demonstrating how common these elements, and resistances, are in the general population. Similarly two recent surveys of plasmids from endodontic derived enterococci identified a large number of different replicons containing a larger number of different resistance genes (Song et al., 2013; Wardal et al., 2013).

\section{METABOLIC ADAPTABILITY}

An interesting example of the influence of HGT on the metabolic capability is provided by the lactobacilli. Mammalian associated lactobacilli are common in the human gastrointestinal tract and in the oral cavity. A recent report has described the catabolic versatility of the different species found in this environment and shown that the ability to use dietary carbohydrates is commonly associated with the acquisition of a particular plasmid encoding the relevant metabolic pathways (O’Donnell et al., 2013). One interesting and well characterized strain is Lactobacillus salivarius UCC118 which was originally isolated from the terminal ileum of a patient undergoing reconstructive surgery on their urinary tract (Claesson et al., 2006). This strain contains a $242 \mathrm{~kb}$ megaplasmid designated pMP118 and two cryptic plasmids ( $\mathrm{Li}$ et al., 2007; O'Donnell et al., 2013). The pMP118 megaplasmid contains, among others, genes predicted to encode proteins involved in pentose and polyol utilization and genes involved in glycolysis making this particular plasmid extremely beneficial to the carrying strains in carbohydrate rich environments such as the oral cavity and GI tract.

\section{HORIZONTAL GENE TRANSFER AND EXTRACELLULAR DNA}

The molecular mechanisms of HGT have been investigated in great detail (Frost et al., 2005; Thomas and Nielsen, 2005). While the source of DNA for HGT through mechanisms like conjugation and transduction is obvious, the generation of DNA in the oral biofilm for transformation of competent bacteria is not well understood. In general, DNA for transformation has to be extracellular DNA accessible for competent bacteria. A regulatory relationship between competence development and the generation of eDNA has been shown for pneumococci in vitro 
(Steinmoen et al., 2002; Moscoso and Claverys, 2004), where the release of chromosomal DNA is part of a lytic process controlled by the competence system, termed fratricide (Claverys et al., 2007). The regulatory coordination of DNA release and competence development ensures that the population wide decision to direct energy toward competence development is rewarded by providing the substrate for uptake at the same time. Taking in consideration that an initial clonal population would diverge due to mutation, the extracellular DNA generated during competence development would have enough diversity (mutations) that could favor establishment of new phenotypic traits under the right selective pressure (Luria and Delbrück, 1943). The homologous extracellular DNA released by a competent population of pneumococcus would facilitate easy integration via homologous recombination. The homologous extracellular DNA, however, might pose an evolutionary disadvantage by not providing complex diversity, e.g., genes for new or alternative metabolic pathways or antimicrobial resistance genes as discussed above. Therefore, diversity is most likely achieved by incorporating heterologous DNA from species that are ecologically similar and not of clonal origin (Smillie et al., 2011). This diversity is actually provided in human associated bacterial communities, such as the oral biofilm.

\section{EXTRACELLULAR DNA IN THE ORAL CAVITY}

A prominent genus of the oral biofilm is Streptococcus and competence development is wide spread among this genus (Rosan and Lamont, 2000; Martin et al., 2006; Havarstein, 2010). The biofilm environment of oral streptococci creates a special situation due to the high cell density and species richness (Kreth et al., 2009). Several seminal findings show that oral streptococci are able to co-aggregate with other bacterial species to built up the mature oral biofilm community, which is one of the most diverse human associated communities identified so far (Valm et al., 2011 and references in Kolenbrander et al., 2006). This diversity does not only create cooperation, but also fierce competition (Kreth et al., 2011). Although, the release of eDNA is most-likely mechanistically explained by bacterial lysis, the molecular details and motivation might be diverse.

\section{EXPERIMENTALLY CONFIRMED MECHANISMS FOR EDNA RELEASE BACTERIOCIN DEPENDENT EDNA RELEASE}

That bacterial competition causes the release of DNA has been shown (Kreth et al., 2005a; Johnsborg et al., 2008). Initial investigations between the clinically relevant antagonism of $S$. mutans and oral commensal $S$. gordonii have revealed an interesting mechanism of eDNA release. The molecular basis for this antagonism is dependent on bacteriocin production (Kreth et al., 2005a). Bacteriocins are antimicrobial peptides inhibitory toward competing bacterial species. S. mutans produces a wide array of bacteriocins and several are regulated by the genetic competence system (Merritt and Qi, 2012). The regulation is due to a specific binding site for the ComE transcriptional regulator found in the promoter sequence of several bacteriocins (van der Ploeg, 2005; Kreth et al., 2006). Once ComE becomes phosphorylated during the activation of the competence cascade, it can bind to the respective bacteriocin gene promoters and activate transcription, while also activating the genes responsible for DNA uptake and homologous recombination. S. mutans therefore coordinates its bacteriocin production with competence development (Kreth et al., 2005a), reminiscent of what has been shown for S. pneumoniae. The significant difference is that the production of these competence-regulated bacteriocins causes the release of DNA from surrounding competitors, not from itself. Dual species, in vitro culture experiments with $S$. mutans and S. gordonii have confirmed that induction of the competence system with $S$. mutans specific competence stimulating peptide can result in the release and transfer of transforming DNA from S. gordonii to S. mutans (Kreth et al., 2005a). Interestingly, the oral bacterial species most susceptible to the bacteriocins under the control of the competence system (namely mutacin IV, V, VI, and Smb) are closely related to S. mutans (Merritt and Qi, 2012). This seems to be an ideal mechanism to ensure the availability of DNA with some evolutionary distance but close enough for a high chance of chromosomal integration via homologous recombination. In a recent review about mutacins of S. mutans, Merritt and Qi explain the potential ecological role of the coordinated competence and mutacin regulation. $S$. mutans is not an early colonizer and therefore has to face stiff competition from species like $S$. sanguinis and $S$. gordonii, which are abundant species during early biofilm development. By producing mutacins controlled by the competence system, $S$. mutans can eliminate the competition potentially freeing occupied space for its own colonization. The released DNA from the closely related species can easily be taken up and has a high potential to provide new genotypic traits. Conversely, other non-related early colonizers like Actinomyces are not targeted by competence-regulated mutacins (Merritt and Qi, 2012). It is tempting to speculate that this is due to the low chance for integration of DNA from distant species into the streptococcal chromosome. In addition, uptake of extracellular DNA released by the action of competence-regulated mutacins might be mainly for homologous recombination and not as a food source or for the generation of DNA building blocks. Competence development in streptococci might in general induce bacteriocins or lytic enzymes to cause lysis of evolutionary related species, as discussed in the next section, to serve in the acquisition of new genetic traits or for DNA repair.

\section{MUREIN HYDROLASE DEPENDENT eDNA RELEASE}

The importance of competence and HGT in its ecological context becomes evident when we revisit the aforementioned pneumococcal fratricide. Initially investigated only in pure single species cultures, fratricide seemed to be an event directed toward its own kind (Claverys et al., 2007). However, in a recent study Johnsborg et al demonstrated that fratricide has a broader ecological impact (Johnsborg et al., 2008). S. pneumoniae resides in a niche, the oral cavity and nasopharynx that is also inhabited by closely related streptococci like S. mitis and S. oralis (Dewhirst et al., 2010). Therefore it is not surprising that pneumococcal competence regulated fratricide and the release of DNA affects nearby species. The center of the pneumococcal fratricide is the murein hydrolase CbpD (Wei and Havarstein, 2012). In a concerted action of the autolytic enzymes LytA, LytC and CbpD target cells are 
lysed to release DNA (Eldholm et al., 2009). While lytA and lyt $C$ are constitutively expressed with an increase of lyt $A$ expression during competence development, $c b p D$ is only expressed in competent cells (Johnsborg et al., 2008). Co-cultivation of S. pneumoniae with the closely related $S$. mitis or S. oralis demonstrated that $\mathrm{CbpD}$ is required for cross species lysis and deletion of $\mathrm{CbpD}$ abolished the ability. Further investigation demonstrated that competence induced cell lysis significantly increases HGT between species possessing the CbpD lysis mechanism (Johnsborg et al., 2008; Eldholm et al., 2010). What is the ecological implication? Competence is regulated by a small peptide, termed CSP (competence stimulating peptide), which is secreted and accumulates in the extracellular environment to trigger competence development in a quorum sensing dependent way (Johnsborg and Havarstein, 2009). The CSP sequence is strain and species specific (Johnsborg et al., 2007). In the nasopharynx and oral cavity a diverse number of different CSP pherogroups exist. Once one pherogroup starts to develop competence it also produces the ComM protein rendering the cells immune to the muralytic attack of CbpD. Other pherotypes not developing competence at the same pace, for example due to a lower initial density can now be attacked and the extracellular DNA released during the attack can be taken up by the competent community (Johnsborg et al., 2008; Eldholm et al., 2010). Interestingly, in a follow up study it was shown that the muralytic activity of $\mathrm{CbpD}$ at the target cells is dependent on its functional binding to choline-decorated teichoic acids. This limits cross-species attack to streptococcal species with choline-decorated teichoic acids such as $S$. mitis and $S$. oralis (Eldholm et al., 2010). Incidentally, S. mitis and S. pneumoniae both belong to the mitis group of streptococci and homologous recombination has been discussed as a major driving force for their evolution reflected by a mosaic structure in several gene sequences (Kilian et al., 2008).

\section{SELF-ACTING INTRACELLULAR BACTERIOCIN DEPENDENT EDNA RELEASE}

While the action of $\mathrm{CbpD}$ can be directed toward itself and other species dependent on the competence state of the respective species, S. mutans has a dedicated bacteriocin for intracellular action against itself (Perry et al., 2009). The production of this bacteriocin, termed $\mathrm{CipB}$ or mutacin V, is also under the control of the competence system and is stress induced. CipB activity against itself is due to intracellular accumulation in the producer, therefore strictly autolytic. In general, stress situations like low antibiotic concentrations, high cell density and oxygen can induce the competence pathway (Claverys et al., 2006). It is believed that competence and lysis would allow the exchange of fitnessenhancing DNA under those stress conditions (Perry et al., 2009). Since it was shown that the CipB induced lysis only occurs in a sub fraction of cells a valid question is how beneficial the extracellular DNA can be? It is well established that antibiotics can cause DNA damage (Cheng et al., 2013; Dwyer et al., 2014). However, this requires active metabolism and DNA replication. If DNA is released into the environment, the mutagenic potential of certain antibiotics is not working. Hence, cells with damaged DNA could take up the released DNA from its own kind for repair. Obviously this works also in the other direction; if DNA mutation happened due to the presence of antibiotic stress, cells could benefit from the mutated and released DNA, if selection pressure establishes the incorporated DNA as fitness enhancing.

The complexity of bacteriocin production and regulation is best understood in S. mutans (Merritt and Qi, 2012). However, the cross-species attack in addition to the internal action of CipB raises the question about the coordination of bacteriocin production. Several mutations in other global regulatory proteins abolish bacteriocin production indicating that the network controlling bacteriocin production is intricate (Chong et al., 2008; Okinaga et al., 2010; Xie et al., 2010). The fluctuating environment of $S$. mutans makes it certain that there are yet to be identified regulatory mechanisms fine tuning bacteriocins production, competence and transformation dependent on environmental signals. In addition, it is not entirely clear when the bacteriocins are produced in the ecological context in vivo. Surprisingly, there is a great diversity of bacteriocins produced by different S. mutans strains, but all investigated strains produce bacteriocins indicating the importance of this mechanism to ensure the availability of extracellular DNA (Merritt and Qi, 2012).

\section{$\mathrm{H}_{2} \mathrm{O}_{2}$ DEPENDENT eDNA RELEASE}

A very different mechanism of extracellular DNA generation is used by commensal streptococci S. gordonii and S. sanguinis (Kreth et al., 2008). Initial investigations on the dual species antagonism with $S$. mutans concentrated on bacteriocin production (Kreth et al., 2005a,b). But the commensals are not the mere victims of this antagonism. S. sanguinis and S. gordonii can inhibit S. mutans in a very efficient way using hydrogen peroxide $\left(\mathrm{H}_{2} \mathrm{O}_{2}\right)$, and compared to the commensals itself, $S$. mutans is highly $\mathrm{H}_{2} \mathrm{O}_{2}$ susceptible (Kreth et al., 2008). Interestingly, the production of $\mathrm{H}_{2} \mathrm{O}_{2}$ is intimately correlated to the release of DNA. The enzyme responsible for the production of $\mathrm{H}_{2} \mathrm{O}_{2}$ in S. sanguinis and S. gordonii was identified as pyruvate oxidase or $\mathrm{SpxB}$. $\mathrm{SpxB}$ is an oxido-reductase that catalyzes the conversion of pyruvate, inorganic phosphate $(\mathrm{Pi})$ and molecular oxygen $\left(\mathrm{O}_{2}\right)$ to $\mathrm{H}_{2} \mathrm{O}_{2}$, carbon dioxide $\left(\mathrm{CO}_{2}\right)$ and the high-energy phosphoryl group donor acetyl phosphate in an aerobic environment. Knock-out studies with putative pyruvate oxidase orthologs in S. sanguinis and S. gordonii confirmed $\mathrm{SpxB}$ as main $\mathrm{H}_{2} \mathrm{O}_{2}$ producer (Kreth et al., 2008). However, the production of growth inhibiting amounts of $\mathrm{H}_{2} \mathrm{O}_{2}$ is not exclusive to the pyruvate oxidase. Mutational studies with Streptococcus oligofermentans showed that at least two other enzymes in addition to the pyruvate oxidase are capable of producing growth-inhibiting amounts of $\mathrm{H}_{2} \mathrm{O}_{2}$. The lactate oxidase LctO catalyzes the formation of pyruvate and $\mathrm{H}_{2} \mathrm{O}_{2}$ from L-lactate and oxygen and an L-amino acid oxidase generates $\mathrm{H}_{2} \mathrm{O}_{2}$ from amino acids and peptones. Antagonism assays of $S$. oligofermentans and $S$. mutans grown in dual species biofilms demonstrated that LctO dependent $\mathrm{H}_{2} \mathrm{O}_{2}$ production is sufficient to antagonize $S$. mutans in an $\mathrm{SpxB}$ mutant. The role of the L-amino acid oxidase in interspecies competition is not clear since its inhibiting activity is only visible in a lctO/spxB double knock-out mutant (Tong et al., 2007, 2008; Liu et al., 2012). In general, $\mathrm{SpxB}$ is a very conserved enzyme encoded by several oral streptococci, including the aforementioned streptococci as well as $S$. oralis, $S$. mitis as abundant members of the oral biofilm 
(Zhu and Kreth, 2012; Zhu et al., 2014). Expression of spxB in the oral biofilm has recently been confirmed pointing to its active biological function during biofilm development (Zhu et al., 2014). The release of chromosomal DNA into the environment by $S$. gordonii and $S$. sanguinis is closely associated with the production of $\mathrm{H}_{2} \mathrm{O}_{2}$ and an SpxB deletion affected the release significantly (Kreth et al., 2008). In agreement with a diminished production of $\mathrm{H}_{2} \mathrm{O}_{2}$ under anaerobic conditions, a significant reduced concentration of extracellular DNA was detected under oxygen limited growth conditions (Itzek et al., 2011). Interestingly, addition of $\mathrm{H}_{2} \mathrm{O}_{2}$ to anaerobically grown cells does induce DNA release. The $\mathrm{H}_{2} \mathrm{O}_{2}$ induced release process is not entirely understood. An obvious time delay was observed between the addition of $\mathrm{H}_{2} \mathrm{O}_{2}$ and the first detectable amounts of extracellular DNA, suggesting that $\mathrm{H}_{2} \mathrm{O}_{2}$ does not induce immediate lysis of the bacterial cells. No release was observed when cells were treated with chloramphenicol, a known protein biosynthesis inhibitor and traditionally used to show that a process requires newly synthesized proteins. A possible signal for the cell to release DNA could be $\mathrm{H}_{2} \mathrm{O}_{2}$ induced DNA damage. Treatment with DNA damaging agents like UV-light and mitomycin $\mathrm{C}$ also triggered the release of DNA under anaerobic conditions (Itzek et al., 2011). Further mechanistic studies showed that the release process seems to be a lytic process (Xu and Kreth, 2013), but different from the complete cell lysis observed for the DNA release in pneumococci and enterococci since extracellular DNA release can be induced by $\mathrm{H}_{2} \mathrm{O}_{2}$ without any obvious bacterial cell lysis (Itzek et al., 2011). A connection of $\mathrm{H}_{2} \mathrm{O}_{2}$ dependent lysis and extracellular DNA release with competence development is not surprising considering the already described examples for other streptococci. S. gordonii expresses the murein hydrolase, LytF. In fact, $l y t F$ is only expressed during competence because its expression is under the control of the competence stimulating peptide CSP. This observation is reminiscent of the expression of $\mathrm{CbpD}$ in S. pneumoniae and LytF has been proposed as functional analog of CbpD. DNA transfer experiments relying on LytF dependent cell lysis and subsequent DNA uptake by $S$. gordonii showed that most cells are protected from the muralytic activity of LytF (Berg et al., 2012). This is in agreement with the observed lysis resistant population in $\mathrm{S}$. gordonii after $\mathrm{H}_{2} \mathrm{O}_{2}$ addition (Itzek et al., 2011). A close association, however, of $\mathrm{H}_{2} \mathrm{O}_{2}$ induced release of DNA and competence development is evident since cells grown under $\mathrm{H}_{2} \mathrm{O}_{2}$ producing conditions are also induced for competence development (Itzek et al., 2011). Interestingly, competence development in S. pneumoniae can be initiated by mitomycin C induced DNA damage, which also leads to the release of DNA similar to what was reported for S. gordonii (Prudhomme et al., 2006).

Combining the experimental findings in S. pneumoniae and S. gordonii a clearer picture emerges about the association and ecological advantage of $\mathrm{H}_{2} \mathrm{O}_{2}$ induced DNA release with the adaptation of oral streptococci to stress. S. gordonii and probably other $\mathrm{H}_{2} \mathrm{O}_{2}$ producing oral streptococci release DNA into the environment as a consequence of DNA damage. This pool of released DNA likely contains mutations in various genes because of the DNA damage. If such mutated DNA is taken up and integrated into the chromosome, the transformation event would lead to a bacterium able to grow and out compete bacteria without the respective mutation under selective conditions or as a template for the repair of stress-induced DNA damage.

\section{LIMITATIONS OF HORIZONTAL GENE TRANSFER}

The successful transfer of a new genetic trait is dependent on several events. In the case of eDNA, the genetic material needs to persist in the environment long enough to be taken up by a competent bacterium. The eDNA integrity and persistence is compromised by host and bacterial derived extracellular nucleases (Kishi et al., 2001; Palmer et al., 2012). Once taken up by competent bacteria, eDNA is subject to cellular defense mechanism which have evolved to prevent the invasion and incorporation of potentially harmful DNA. Restriction modification systems are a well-characterized and common bacterial defense system that methylates genomic DNA at specific target sequences. These sequences are also recognized and cleaved by cognate restriction enzymes when they are not methylated, which will likely be the case on newly acquired, foreign DNA that is taken up by the bacterium, thus preventing integration into the chromosome (Bickle and Kruger, 1993). Another important defense mechanism is the CRISPR-Cas system (clustered regularly interspaced short palindromic repeats), which is considered a bacterial immune system. It is an adaptive and inheritable system which recognizes and destroys foreign DNA therefore preventing infection by bacteriophages, transposons and plasmids. It is an RNA based protection mechanism, which stores parts of the DNA of previously encountered bacteriophage, transposons and plasmids in the CRISPR chromosomal locus. The cell is therefore able to prevent potential harmful DNA of integrating into the chromosome by RNA interference using the stored information of the CRISPR (Gasiunas et al., 2014). In addition, an important limitation is the selective pressure for the respective new genetic trait. If there is no advantage gained by the host bacterium to keep the acquired DNA there will be no selective pressure to maintain it.

\section{CONCLUSIONS}

The increasing amount of evidence for HGT in the human oral cavity shows that these processes are important in the adaptability of the oral community. The nature of some of the evolutionary strategies involving HGT is much more complex than simple acquisition of DNA released from dead cells or acquisition of a plasmid or transposon from a donor member of the oral community. More evidence for this is found in oral metagenomes; it has recently been found that the incidence of CRISPRs and the numbers of MGEs associated with oral cavity derived metagenomes is far more than in the GI tract of man (Zhang et al., 2013). The pervasiveness of HGT and the incredibly large number of MGEs found in oral bacteria is arguably a result of the oral environment or at the very least is influenced and selected by the conditions found within it. In other words, if the oral bacterial consortium requires a specific gene, for example conferring antibiotic resistance, it is most-likely already present and only needs to be acquired by the various mechanisms of HGT discussed. 


\section{ACKNOWLEDGMENTS}

Work in the laboratory of Adam P. Roberts was funded by the Commission of the European Communities, specifically the Infectious Diseases research domain of the Health theme of the 7th Framework Programme, contract 241446, "The effects of antibiotic administration on the emergence and persistence of antibiotic-resistant bacteria in humans and on the composition of the indigenous microbiotas at various body sites." Jens Kreth would like to acknowledge funding through NIH-NIDCR grant R01DE021726.

\section{REFERENCES}

Al-Jarbou, A. N. (2012). Genomic library screening for viruses from the human dental plaque revealed pathogen-specific lytic phage sequences. Curr. Microbiol. 64, 1-6. doi: 10.1007/s00284-011-0025-Z

Bachrach, G., Leizerovici-Zigmond, M., Zlotkin, A., Naor, R., and Steinberg, D. (2003). Bacteriophage isolation from human saliva. Lett. Appl. Microbiol. 36, 50-53. doi: 10.1046/j.1472-765X.2003.01262.x

Berg, K. H., Ohnstad, H. S., and Håvarstein, L. S. (2012). LytF, a novel competenceregulated murein hydrolase in the genus Streptococcus. J. Bacteriol. 194, 627-635. doi: 10.1128/JB.06273-11

Bickle, T. A., and Kruger, D. H. (1993). Biology of DNA restriction. Microbiol. Rev. 57, 434-450.

Chalmers, N. I., Palmer, R. J. Jr., Cisar, J. O., and Kolenbrander, P. E. (2008). Characterization of a Streptococcus sp.-Veillonella sp. community micromanipulated from dental plaque. J. Bacteriol. 190, 8145-8154. doi: 10.1128/JB. 00983-08

Cheng, G., Hao, H., Dai, M., Liu, Z., and Yuan, Z. (2013). Antibacterial action of quinolones: from target to network. Eur. J. Med. Chem. 66, 555-562. doi: 10.1016/j.ejmech.2013.01.057

Chong, P., Drake, L., and Biswas, I. (2008). LiaS regulates virulence factor expression in Streptococcus mutans. Infect. Immun. 76, 3093-3099. doi: 10.1128/IAI.01627-07

Ciric, L., Brouwer, M. S., Mullany, P., and Roberts, A. P. (2014). Minocycline resistance in an oral Streptococcus infantis isolate is encoded by tet(S) on a novel small, low copy number plasmid. FEMS Microbiol. Lett. 353, 106-115. doi: 10.1111/1574-6968.12410

Ciric, L., Ellatif, M., Sharma, P., Patel, R., Song, X., Mullany, P., et al. (2012). Tn916like elements from human, oral, commensal streptococci possess a variety of antibiotic and antiseptic resistance genes. Int. J. Antimicrob. Agents 39, 360-361. doi: 10.1016/j.ijantimicag.2011.12.007

Ciric, L., Mullany, P., and Roberts, A. P. (2011). Antibiotic and antiseptic resistance genes are linked on a novel mobile genetic element: Tn6087. J. Antimicrob. Chemother. 66, 2235-2239. doi: 10.1093/jac/dkr311

Claesson, M. J., van Sinderen, D., and O’Toole, P. W. (2006). The genus Lactobacillus-a genomic basis for understanding its diversity. FEMS Microbiol. Lett. 269, 22-28. doi: 10.1111/j.1574-6968.2006.00596.x

Claverys, J. P., Martin, B., and Håvarstein, L. S. (2007). Competence-induced fratricide in streptococci. Mol. Microbiol. 64, 1423-1433. doi: 10.1111/j.13652958.2007.05757.x

Claverys, J. P., Prudhomme, M., and Martin, B. (2006). Induction of competence regulons as a general response to stress in gram-positive bacteria. Annu. Rev. Microbiol. 60, 451-475. doi: 10.1146/annurev.micro.60.080805.142139

Connell, S. R., Tracz, D. M., Nierhaus, K. H., and Taylor, D. E. (2003). Ribosomal protection proteins and their mechanism of tetracycline resistance. Antimicrob. Agents Chemother. 47, 3675-3681. doi: 10.1128/AAC.47.12.3675-3681.2003

Curtis, M. A., Zenobia, C., and Darveau, R. P. (2011). The relationship of the oral microbiota to periodontal health and disease. Cell Host Microbe 10, 302-306. doi: 10.1016/j.chom.2011.09.008

Dewhirst, F. E., Chen, T., Izard, J., Paster, B. J., Tanner, A. C., and Yu, W. H. (2010). The human oral microbiome. J. Bacteriol. 192, 5002-5017. doi: 10.1128/JB.00542-10

Diaz, P. I., Chalmers, N. I., Rickard, A. H., Kong, C., Milburn, C. L., Palmer, R. J. Jr., et al. (2006). Molecular characterization of subject-specific oral microflora during initial colonization of enamel. Appl. Environ. Microbiol. 72, 2837-2848. doi: 10.1128/AEM.72.4.2837-2848.2006
Dwyer, D. J., Belenky, P. A., Yang, J. H., MacDonald, I. C., Martell, J. D., and Takahashi, N. (2014). Antibiotics induce redox-related physiological alterations as part of their lethality. Proc. Natl. Acad. Sci. U.S.A. 111, E2100-E2109. doi: 10.1073/pnas.1401876111

Eldholm, V., Johnsborg, O., Haugen, K., Ohnstad, H. S., and Håvarstein, L. S. (2009). Fratricide in Streptococcus pneumoniae: contributions and role of the cell wall hydrolases CbpD, LytA and LytC. Microbiology 155, 2223-2234. doi: 10.1099/mic.0.026328-0

Eldholm, V., Johnsborg, O., Straume, D., Ohnstad, H. S., Berg, K. H., Hermoso, J. A., et al. (2010). Pneumococcal CbpD is a murein hydrolase that requires a dual cell envelope binding specificity to kill target cells during fratricide. Mol. Microbiol. 76, 905-917. doi: 10.1111/j.1365-2958.2010.07143.x

Frost, L. S., Leplae, R., Summers, A. O., and Toussaint, A. (2005). Mobile genetic elements: the agents of open source evolution. Nat. Rev. Microbiol. 3, 722-732. doi: 10.1038/nrmicro1235

Fulsundar, S., Harms, K., Flaten, G. E., Johnsen, P. J., Chopade, B. A., and Nielsen, K. M. (2014). Gene transfer potential of outer membrane vesicles of Acinetobacter baylyi and effects of stress on vesiculation. Appl. Environ. Microbiol. 80, 3469-3483. doi: 10.1128/AEM.04248-13

Gasiunas, G., Sinkunas, T., and Siksnys, V. (2014). Molecular mechanisms of CRISPR-mediated microbial immunity. Cell. Mol. Life Sci. 71, 449-465. doi: 10.1007/s00018-013-1438-6

Geng, J., Chiu, C. H., Tang, P., Chen, Y., Shieh, H. R., Hu, S., et al. (2012). Complete genome and transcriptomes of Streptococcus parasanguinis FW213: phylogenic relations and potential virulence mechanisms. PLoS ONE 7:e34769. doi: 10.1371/journal.pone.0034769

Hannan, S., Ready, D., Jasni, A. S., Rogers, M., Pratten, J., and Roberts, A. P. (2010). Transfer of antibiotic resistance by transformation with eDNA within oral biofilms. FEMS Immunol. Med. Microbiol. 59, 345-349. doi: 10.1111/j.1574695X.2010.00661.x

Havarstein, L. S. (2010). Increasing competence in the genus Streptococcus. Mol. Microbiol. 78, 541-544. doi: 10.1111/j.1365-2958.2010.07380.x

Itzek, A., Zheng, L., Chen, Z., Merritt, J., and Kreth, J. (2011). Hydrogen peroxide-dependent DNA release and transfer of antibiotic resistance genes in Streptococcus gordonii. J. Bacteriol. 193, 6912-6922. doi: 10.1128/JB.05791-11

Johnsborg, O., Blomqvist, T., Kilian, M., and Havarstein, L. S. (2007). "Biologically active peptides in streptococci," in Molecular Biology of Streptococci, eds R. Hakenbeck, and S. Chhatwal (Wymondham: Horizon Scientific Press), 25-59.

Johnsborg, O., Eldholm, V., Bjørnstad, M. L., and Håvarstein, L. S. (2008). A predatory mechanism dramatically increases the efficiency of lateral gene transfer in Streptococcus pneumoniae and related commensal species. Mol. Microbiol. 69, 245-253. doi: 10.1111/j.1365-2958.2008.06288.x

Johnsborg, O., and Havarstein, L. S. (2009). Regulation of natural genetic transformation and acquisition of transforming DNA in Streptococcus pneumoniae. FEMS Microbiol. Rev. 33, 627-642. doi: 10.1111/j.1574-6976.2009.00167.x

Kerr, J. E., Abramian, J. R., Dao, D. H., Rigney, T. W., Fritz, J., Pham, T., et al. (2014). Genetic exchange of fimbrial alleles exemplifies the adaptive virulence strategy of Porphyromonas gingivalis. PLoS ONE 9:e91696. doi: 10.1371/journal.pone.0091696

Kilian, M., Poulsen, K., Blomqvist, T., Håvarstein, L. S., Bek-Thomsen, M., Tettelin, H., et al. (2008). Evolution of Streptococcus pneumoniae and its close commensal relatives. PLoS ONE 3:e2683. doi: 10.1371/journal.pone.0002683

Kishi, K., Yasuda, T., and Takeshita, H. (2001). DNase I: structure, function, and use in medicine and forensic science. Leg. Med. 3, 69-83. doi: 10.1016/S13446223(01)00004-9

Kolenbrander, P. E., Palmer, R. J. Jr., Rickard, A. H., Jakubovics, N. S., Chalmers, N. I., and Diaz, P. I. (2006). Periodontol 2000 42, 47-79. doi: 10.1111/j.16000757.2006.00187.x

Kreth, J.1., Merritt, J., and Qi, F. (2009). Bacterial and host interactions of oral streptococci. DNA Cell Biol. 28, 397-403. doi: 10.1089/dna.2009.0868

Kreth, J., Merritt, J., Qi, F., Dong, X., and Shi, W. (2011). "Antagonistic, synergistic, and counteroffensive strategies for streptococcal interspecies interactions," in Oral Microbial Communities: Genomic Inquiry and Interspecies Communication, ed P. E. Kolenbrander (Washington, DC: USA ASM Press), 331-343.

Kreth, J., Merritt, J., Shi, W., and Qi, F. (2005a). Co-ordinated bacteriocin production and competence development: a possible mechanism for taking up DNA from neighbouring species. Mol. Microbiol. 57, 392-404. doi: 10.1111/j.13652958.2005.04695.x 
Kreth, J., Merritt, J., Shi, W., and Qi, F. (2005b). Competition and coexistence between Streptococcus mutans and Streptococcus sanguinis in the dental biofilm. J. Bacteriol. 187, 7193-7203. doi: 10.1128/JB.187.21.7193-7203.2005

Kreth, J., Merritt, J., Zhu, L., Shi, W., and Qi, F. (2006). Cell density- and ComE-dependent expression of a group of mutacin and mutacin-like genes in Streptococcus mutans. FEMS Microbiol. Lett. 265, 11-17. doi: 10.1111/j.15746968.2006.00459.x

Kreth, J., Zhang, Y., and Herzberg, M. C. (2008). Streptococcal antagonism in oral biofilms: Streptococcus sanguinis and Streptococcus gordonii interference with Streptococcus mutans. J. Bacteriol. 190, 4632-4640. doi: 10.1128/JB.00276-08

Li, Y., Canchaya, C., Fang, F., Raftis, E., Ryan, K. A., van Pijkeren, J. P., et al. (2007). Distribution of megaplasmids in Lactobacillus salivarius and other lactobacilli. J. Bacteriol. 189, 6128-6139. doi: 10.1128/JB.00447-07

Liao, S., Klein, M. I., Heim, K. P., Fan, Y., Bitoun, J. P., Ahn, S. J., et al. (2014). Streptococcus mutans extracellular DNA is upregulated during growth in biofilms, actively released via membrane vesicles, and influenced by components of the protein secretion machinery. J. Bacteriol. 196, 2355-2366. doi: 10.1128/JB.01493-14

Lindsay, J. (2014). Staphylococcus aureus genomics and the impact of horizontal gene transfer. Int. J. Med. Microbiol. 304, 103-109. doi: 10.1016/j.ijmm.2013. 11.010

Liu, L., Tong, H., and Dong, X. (2012). Function of the pyruvate oxidase-lactate oxidase cascade in interspecies competition between Streptococcus oligofermentans and Streptococcus mutans. Appl. Environ. Microbiol. 78, 2120-2127. doi: 10.1128/AEM.07539-11

Luria, S. E., and Delbrück, M. (1943). Mutations of bacteria from virus sensitivity to virus resistance. Genetics 28, 491-511.

Martin, B., Quentin, Y., Fichant, G., and Claverys, J. P. (2006). Independent evolution of competence regulatory cascades in streptococci? Trends Microbiol. 14, 339-345. doi: 10.1016/j.tim.2006.06.007

Mashburn-Warren, L. M., and Whiteley, M. (2006). Special delivery: vesicle trafficking in prokaryotes. Mol. Microbiol. 61, 839-846. doi: 10.1111/j.13652958.2006.05272.x

Merritt, J., and Qi, F. (2012). The mutacins of Streptococcus mutans: regulation and ecology. Mol. Oral Microbiol. 27, 57-69. doi: 10.1111/j.2041-1014.2011. 00634. $\mathrm{x}$

Moscoso, M., and Claverys, J. P. (2004). Release of DNA into the medium by competent Streptococcus pneumoniae: kinetics, mechanism and stability of the liberated DNA. Mol. Microbiol. 54, 783-794. doi: 10.1111/j.1365-2958.2004. 04305.x

O’Donnell, M. M., O’Toole, P. W., and Ross, R. P. (2013). Catabolic flexibility of mammalian-associated lactobacilli. Microb. Cell Fact. 12:48. doi: 10.1186/14752859-12-48

Okinaga, T., Niu, G., Xie, Z., Qi, F., and Merritt, J. (2010). The hdrRM operon of Streptococcus mutans encodes a novel regulatory system for coordinated competence development and bacteriocin production. J. Bacteriol. 192, 1844-1852. doi: 10.1128/JB.01667-09

Olsen, I., Tribble, G. D., Fiehn, N. E., and Wang, B. Y. (2013). Bacterial sex in dental plaque. J. Oral Microbiol. 5. doi: 10.3402/jom.v5i0.20736

Palmer, L. J., Chapple, I. L., Wright, H. J., Roberts, A., and Cooper, P. R. (2012). Extracellular deoxyribonuclease production by periodontal bacteria. J. Periodontal Res. 47, 439-445. doi: 10.1111/j.1600-0765.2011.01451.x

Pérez-Cruz, C., Carrión, O., Delgado, L., Martinez, G., López-Iglesias, C., and Mercade, E. (2013). New type of outer membrane vesicle produced by the Gram-negative bacterium Shewanella vesiculosa M7T: implications for DNA content. Appl. Environ. Microbiol. 79, 1874-1881. doi: 10.1128/AEM. 03657-12

Perry, J. A., Jones, M. B., Peterson, S. N., Cvitkovitch, D. G., and Lévesque, C. M. (2009). Peptide alarmone signalling triggers an auto-active bacteriocin necessary for genetic competence. Mol. Microbiol. 72, 905-917. doi: 10.1111/j.13652958.2009.06693.x

Pride, D. T., Salzman, J., Haynes, M., Rohwer, F., Davis-Long, C., White, R. A. 3rd., et al. (2012). Evidence of a robust resident bacteriophage population revealed through analysis of the human salivary virome. ISME J. 6, 915-926. doi: 10.1038/ismej.2011.169

Prudhomme, M., Attaiech, L., Sanchez, G., Martin, B., and Claverys, J. P. (2006). Antibiotic stress induces genetic transformability in the human pathogen Streptococcus pneumoniae. Science 313, 89-92. doi: 10.1126/science. 1127912
Ready, D., Pratten, J., Roberts, A. P., Bedi, R., Mullany, P., and Wilson, M. (2006). Potential role of Veillonella spp. as a reservoir of transferable tetracycline resistance in the oral cavity. Antimicrob. Agents Chemother. 50, 2866-2868. doi: 10.1128/AAC.00217-06

Richards, V. P., Palmer, S. R., Pavinski Bitar, P. D., Qin, X., Weinstock, G. M., Highlander, S. K., et al. (2014). Phylogenomics and the dynamic genome evolution of the genus Streptococcus. Genome Biol. Evol. 6, 741-753. doi: 10.1093/gbe/evu048

Roberts, A. P., Cheah, G., Ready, D., Pratten, J., Wilson, M., and Mullany, P. (2001). Transfer of Tn916-like elements in microcosm dental plaques. Antimicrob. Agents Chemother. 45, 2943-2946. doi: 10.1128/AAC.45.10.2943-2946.2001

Roberts, A. P., and Mullany, P. (2006). Genetic basis of horizontal gene transfer among oral bacteria. Periodontol. 2000 42, 36-46. doi: 10.1111/j.16000757.2006.00149.x

Roberts, A. P., and Mullany, P. (2010). Oral biofilms: a reservoir of transferable, bacterial, antimicrobial resistance. Expert Rev. Anti Infect. Ther. 8, 1441-1450. doi: 10.1586/eri.10.106

Roberts, A. P., and Mullany, P. (2011). Tn916-like genetic elements: a diverse group of modular mobile elements conferring antibiotic resistance. FEMS Microbiol. Rev. 35, 856-871. doi: 10.1111/j.1574-6976.2011. 00283.x

Roberts, A. P., Pratten, J., Wilson, M., and Mullany, P. (1999). Transfer of a conjugative transposon, Tn5397 in a model oral biofilm. FEMS Microbiol. Lett. 177, 63-66. doi: 10.1111/j.1574-6968.1999.tb13714.x

Rosan, B., and Lamont, R. J. (2000). Dental plaque formation. Microbes Infect. 2, 1599-1607. doi: 10.1016/S1286-4579(00)01316-2

Sandmeier, H., van Winkelhoff, A. J., Bär, K., Ankli, E., Maeder, M., and Meyer, J. (1995). Temperate bacteriophages are common among Actinobacillus actinomycetemcomitans isolates from periodontal pockets. J. Periodontal Res. 30, 418-425. doi: 10.1111/j.1600-0765.1995.tb01296.x

Seville, L. A., Patterson, A. J., Scott, K. P., Mullany, P., Quail, M. A., Parkhill, J., et al. (2009). Distribution of tetracycline and erythromycin resistance genes among human oral and fecal metagenomic DNA. Microb. Drug Resist. 15, 159-166. doi: 10.1089/mdr.2009.0916

Smillie, C. S., Smith, M. B., Friedman, J., Cordero, O. X., David, L. A., and Alm, E. J. (2011). Ecology drives a global network of gene exchange connecting the human microbiome. Nature 480, 241-244. doi: 10.1038/nature 10571

Song, X., Sun, J., Mikalsen, T., Roberts, A. P., and Sundsfjord, A. (2013). Characterisation of the plasmidome within Enterococcus faecalis isolated from marginal periodontitis patients in Norway. PLoS ONE 8:e62248. doi: 10.1371/journal.pone.0062248

Steinmoen, H., Knutsen, E., and Håvarstein, L. S. (2002). Induction of natural competence in Streptococcus pneumoniae triggers lysis and DNA release from a subfraction of the cell population. Proc. Natl. Acad. Sci. U.S.A. 99, 7681-7686. doi: 10.1073/pnas.112464599

Stevens, R. H., Porras, O. D., and Delisle, A. L. (2009). Bacteriophages induced from lysogenic rootcanal isolates of Enterococcus faecalis. Oral Microbiol. Immunol. 24, 278-284. doi: 10.1111/j.1399-302X.2009.00506.x

Thomas, C. M., and Nielsen, K. M. (2005). Mechanisms of, and barriers to, horizontal gene transfer between bacteria. Nat. Rev. Microbiol. 3, 711-721. doi: 10.1038/nrmicro1234

Tong, H., Chen, W., Merritt, J., Qi, F., Shi, W., and Dong, X. (2007). Streptococcus oligofermentans inhibits Streptococcus mutans through conversion of lactic acid into inhibitory $\mathrm{H} 2 \mathrm{O} 2$ : a possible counteroffensive strategy for interspecies competition. Mol. Microbiol. 63, 872-880. doi: 10.1111/j.1365-2958.2006. 05546.x

Tong, H., Chen, W., Shi, W., Qi, F., and Dong, X. (2008). SO-LAAO, a novel L-amino acid oxidase that enables Streptococcus oligofermentans to outcompete Streptococcus mutans by generating $\mathrm{H} 2 \mathrm{O} 2$ from peptone. J. Bacteriol. 190, 4716-4721. doi: 10.1128/JB.00363-08

Tribble, G. D., Lamont, G. J., Progulske-Fox, A., and Lamont, R. J. (2007). Conjugal transfer of chromosomal DNA contributes to genetic variation in the oral pathogen Porphyromonas gingivalis. J. Bacteriol. 189, 6382-6388. doi: 10.1128/JB.00460-07

Tribble, G. D., Rigney, T. W., Dao, D. H., Wong, C. T., Kerr, J. E., Taylor, B. E., et al. (2012). Natural competence is a major mechanism for horizontal DNA transfer in the oral pathogen Porphyromonas gingivalis. MBio. 3. doi: 10.1128/mBio.00231-11 
Valm, A. M., Mark Welch, J. L., Rieken, C. W., Hasegawa, Y., Sogin, M. L., Oldenbourg, R., et al. (2011). Systems-level analysis of microbial community organization through combinatorial labeling and spectral imaging. Proc. Natl. Acad. Sci. U.S.A. 108, 4152-4157. doi: 10.1073/pnas.1101 134108

van der Ploeg, J. R. (2005). Regulation of bacteriocin production in Streptococcus mutans by the quorum-sensing system required for development of genetic competence. J. Bacteriol. 187, 3980-3989. doi: 10.1128/JB.187.12.39803989.2005

Wade, W. G. (2013). The oral microbiome in health and disease. Pharmacol. Res. 69, 137-143. doi: 10.1016/j.phrs.2012.11.006

Warburton, P. J., Palmer, R. M., Munson, M. A., and Wade, W. G. (2007). Demonstration of in vivo transfer of doxycycline resistance mediated by a novel transposon. J. Antimicrob. Chemother. 60, 973-980. doi: 10.1093/jac/dkm331

Wardal, E., Gawryszewska, I., Hryniewicz, W., and Sadowy, E. (2013). Abundance and diversity of plasmid-associated genes among clinical isolates of Enterococcus faecalis. Plasmid. 70, 329-342. doi: 10.1016/j.plasmid.2013.07.003

Wei, H., and Havarstein, L. S. (2012). Fratricide is essential for efficient gene transfer between pneumococci in biofilms. Appl. Environ. Microbiol. 78, 5897-5905. doi: 10.1128/AEM.01343-12

Willi, K., Sandmeier, H., Kulik, E. M., and Meyer, J. (1997). Transduction of antibiotic resistance markers among Actinobacillus actinomycetemcomitans strains by temperate bacteriophages Aa phi 23. Cell. Mol. Life Sci. 53, 904-910. doi: $10.1007 / \mathrm{s} 000180050109$

Wilson, M. (2005). Microbial Inhabitants of Humans. Their Ecology and Role in Health and Disease. Cambridge: Cambridge University Press.

Xie, Z., Okinaga, T., Niu, G., Qi, F., and Merritt, J. (2010). Identification of a novel bacteriocin regulatory system in Streptococcus mutans. Mol. Microbiol. 78, 1431-1447. doi: 10.1111/j.1365-2958.2010.07417.x

$\mathrm{Xu}, \mathrm{Y}$., and Kreth, J. (2013). Role of LytF and AtlS in eDNA release by Streptococcus gordonii. PLoS ONE 8:e62339. doi: 10.1371/journal.pone.0062339

Yaron, S., Kolling, G. L., Simon, L., and Matthews, K. R. (2000). Vesicle-mediated transfer of virulence genes from Escherichia coli O157:H7 to other enteric bac- teria. Appl. Environ. Microbiol. 66, 4414-4420. doi: 10.1128/AEM.66.10.44144420.2000

Zähner, D., Gandhi, A. R., Yi, H., and Stephens, D. S. (2011). Mitis group streptococci express variable pilus islet 2 pili. PLoS ONE 6:e25124. doi: 10.1371/journal.pone.0025124

Zhang, Q., Rho, M., Tang, H., Doak, T. G., and Ye, Y. (2013). CRISPRCas systems target a diverse collection of invasive mobile genetic elements in human microbiomes. Genome Biol. 14, R40. doi: 10.1186/gb-201314-4-r40

Zhu, L., and Kreth, J. (2012). The role of hydrogen peroxide in environmental adaptation of oral microbial communities. Oxid. Med. Cell. Longev. 2012, 717843. doi: 10.1155/2012/717843

Zhu, L., Xu, Y., Ferretti, J. J., and Kreth, J. (2014). Probing oral microbial functionality-expression of spxB in plaque samples. PLOS ONE 9:e86685. doi: 10.1371/journal.pone.0086685

Conflict of Interest Statement: The authors declare that the research was conducted in the absence of any commercial or financial relationships that could be construed as a potential conflict of interest.

Received: 11 June 2014; accepted: 19 August 2014; published online: 08 September 2014.

Citation: Roberts AP and Kreth J (2014) The impact of horizontal gene transfer on the adaptive ability of the human oral microbiome. Front. Cell. Infect. Microbiol. 4:124. doi: $10.3389 /$ fcimb.2014.00124

This article was submitted to the journal Frontiers in Cellular and Infection Microbiology.

Copyright (c) 2014 Roberts and Kreth. This is an open-access article distributed under the terms of the Creative Commons Attribution License (CC BY). The use, distribution or reproduction in other forums is permitted, provided the original author(s) or licensor are credited and that the original publication in this journal is cited, in accordance with accepted academic practice. No use, distribution or reproduction is permitted which does not comply with these terms. 